\title{
COPIM
}

\section{Library Support for OA Books Workshop: the Southern European perspective.}

\section{Agata Morka}

Published on: Oct 12, 2020

DOI: $10.21428 / 785 a 6451 . c 1 c d 7059$

License: Creative Commons Attribution 4.0 International License (CC-BY 4.0). 
As part of the projects conducted for the COPIM Work Package 2 (Revenue Infrastructures and Management Platform). and OPERAS-P Work Package 6 (Innovation), we are continuing a series of European-based workshops, aiming at gaining a better understanding of the national-specific issues surrounding collective funding for OA books from a library perspective. The fourth online workshop took place on October 8th. This time we invited representatives of three Southern European countries. OA specialists and librarians from Croatia, Greece and Slovenia joined us to discuss how their libraries deal with OA books. From Ljubljana via Zagreb to Athens: we had colleagues sitting down with us, sharing screens, links and their views from different national perspectives.

\section{Up and down}

Asked about the major roadblocks when it comes to supporting OA books the vast majority of participants have stressed the question of lack of funds. During the workshop discussion, we learnt that libraries in all three countries either struggle with minimal budgets or the complete lack thereof. They rely on national, often ministerial funds and have very little say in actual acquisition decisions. It became clear that, if we want to gain serious engagement of Croatia, Greece and Slovenia in any new OA books initiative rather than addressing individual institutions, we should pitch the idea to either national consortia, or go as far as talking to national research foundations and ministries.

While all countries can be proud of their library communities and the bottom-up work that they have put in developing OA initiatives (Croatian HRCAK being a fine example of this approach), a certain topdown intervention seems to be needed, if new OA books initiatives are to gain serious momentum. Participants said that they would be able to help us contact people at national agencies so that we could initiate talks on a national, rather than institutional level.

\section{Will it fit?}

When deciding for or against new OA books initiatives, librarians, even if their individual decision making power is not substantial in the context of centralised national funds, would still look for relevance in their assessment procedure. Will the proposed book portfolio fit into the institution's profile, would the initiative align with institutional missions, to which extent would it fulfil them? Principles of open science have been incorporated, if in theory only, by a relatively large number of HEIs in the region and therefore participants listed the fact if a proposed initiative was developed using an open source software as the most important factor in their decision making process, along sustainability and preservation processes applied.

Participants were more drawn to a collective general structure, offering a coherent, prescribed collection, rather than a plethora of pick and choose options. They stressed that in their countries, but also globally, library collections are still mainly created based on purchased items, with the OA content 
present as an interesting add-on, but still seen as of a somewhat lesser value than the subscription based publications. Since visibility of OA content has risen as a challenge, it was suggested that a special COPIM OA Books Collection could be created and that it should be easily ingestible into library catalogues and discovery tools.

\section{Jezik, $Г \lambda \omega ́ \sigma \sigma \alpha$, language}

When asked about the proportion of academic monographs being published in local languages versus English, representatives of all three countries stated that the main part of the scholarly publishing output is being written in countries' respective mother tongues. Therefore not only should language diversity be acknowledged, but also treated as one of the crucial design specs when developing OA books-related initiatives in Croatia, Slovenia and Greece. The importance of local languages, especially for Humanities and Social Sciences has arisen as a common thread in workshops across Europe: we heard similar voices in Poland and Nordic countries.

\section{Handle with patience}

Participants agreed that a certain mind shift towards a greater awareness of open access importance is needed in all three countries. Currently there is no official national OA policy in Croatia and Greece. Slovenia does have a national OA mandate, however for journals only, not for books. Given the lack of official OA mandates, publishing a monograph in open access is not on the priority list of researchers from these countries. Even more so because none of the represented countries has an OA books specific fund, therefore publishing charges, on the author side, are covered from grants. However, it is important to stress that even in this context some of the universities have established their own OA university presses (see for example the Faculty of Social Sciences and Humanities at the University of Zadar) and some of them publish up to 70 OA monographs per year (the Faculty of Arts at the University of Ljubljana).

Scarcity of human resources and infrastructure, as well as certain suspiciousness towards new products and their commercial character somewhat clouds the enthusiasm for new OA initiatives. There were voices stating that "traditional" print-only publishing, as well as traditional practices of collection building, based on subscription content, dominate the academic libraries landscape and that time is needed to integrate $\mathrm{OA}$ in it. Patience was recommended by the workshop participants as one of the tools needed when planting OA books projects in the Southern European soil.

Thank you to all the participants and their feedback: it was a great opportunity to see how OA books related questions are treated in the south of Europe. 
Our next workshop will focus on three other Southern European countries: this time we will talk to OA specialists from Italy, Spain and Portugal. We are looking forward to hearing their thoughts on the issue of collective funding models for OA books and the role that their libraries can play in them. Stay tuned for the next report!

Photo by Georgios Liakopoulos on Flickr, CC BY-SA 2.0 